\title{
Towards effective youth participation [Arabic]
}

Magued Osman

Hanan Girgis

Follow this and additional works at: https://knowledgecommons.popcouncil.org/departments_sbsr-pgy

Part of the Demography, Population, and Ecology Commons, Family, Life Course, and Society Commons, International Public Health Commons, and the Politics and Social Change Commons How does access to this work benefit you? Let us know!

\section{Recommended Citation}

Osman, Magued and Hanan Girgis. 2016. "Towards effective youth participation [Arabic]," policy brief. Cairo: Population Council. 


\section{الرسائل الأساسية}

تشبر البيانات من المصادر المختلفة إلى عزوف الثباب عن المشاركة السياسية و المجتمعية في

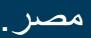

يمكن عزو تراجع المثاركة

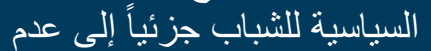

شعور الشباب بجدوى أشكال

المشاركة السياسية في مصر ،

وهو ما بستدعي تغيير نظرة الشباب لجدوى المشاركة السياسية وقدرثه على المثاركة في اتخاذ

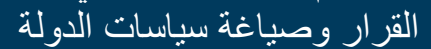

من خلال المثاركة السياسية بأثكالها المختلفة

ضرورة جذب الثباب للمشاركة السباسية و المجتمعية من خلالب إثر الك الثباب في منابعة وتقيبم تنفبذ السياسات و البر امج على التي أرض الواقع على المستوى المحلي، وتوظلف النكنولو جيا في تفعيل مشاركة الثباب.

ضرورة وضع خطة شاملة

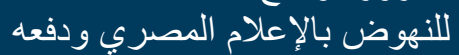
للعب دور إيجابي في تشكيل وجدان ومعارف الثباب المصري لفي الثين وتغيير القيم الحاكمة للشباب.

\section{$\bullet$}

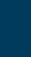




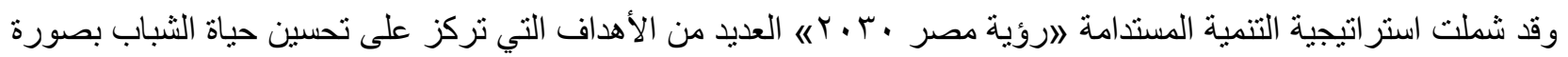

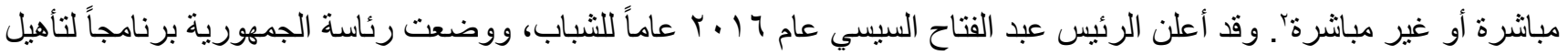

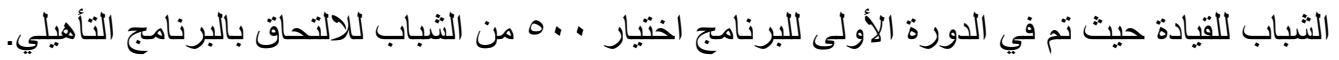

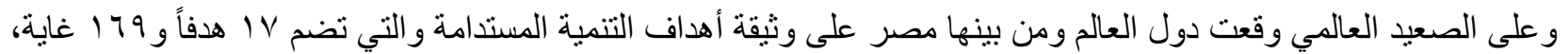

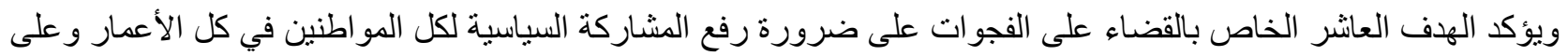

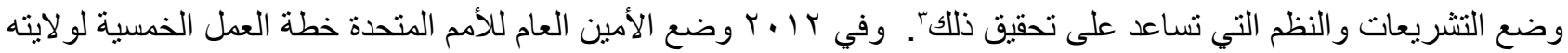

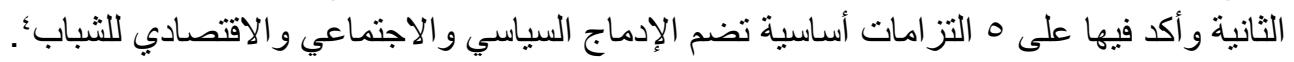

\section{مصادر البيانات:}

تعتمد الورقة على تحليل بيانات عدد من المسوح واسنطلاعات الرأي التي أجريت خلال العامين الماضيين:

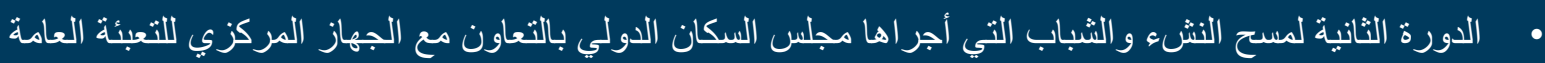

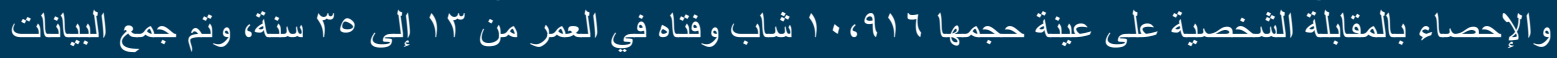

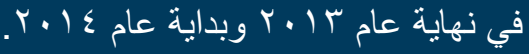

مسح التحو لات الاجتماعية و السياسية في الوطن العربي الذي أجر اه مركز بصيرة بالمقابلة النخصية على عينة ممثلة

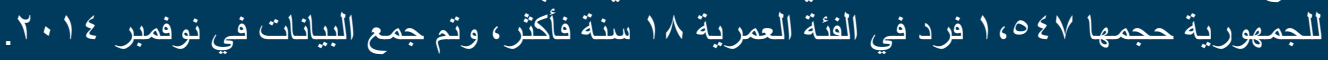
• استطلاع المشاركة السياسية: المدركات و الممارسة الذي أجر اه مركز بصيرة ضمن أنشطة مشروع مسار بالتليفون

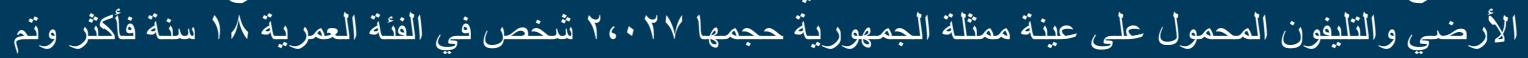

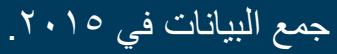

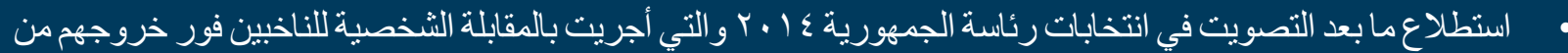

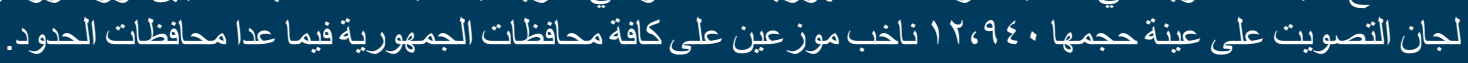

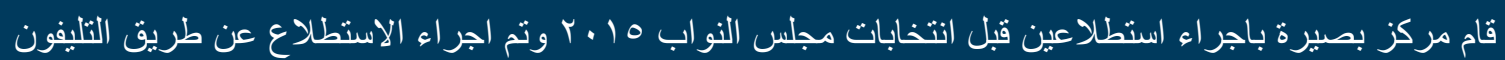

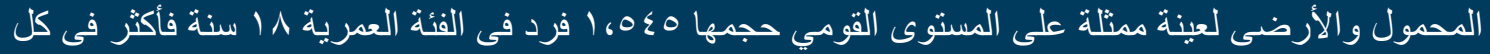
محافظات الجمهورية.

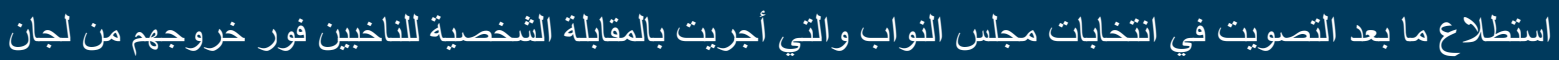

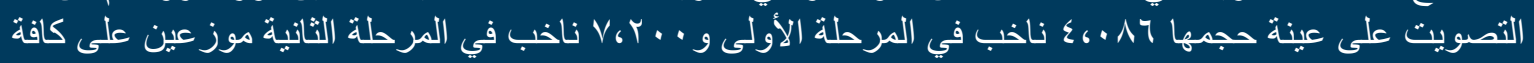
محافظات الجمهورية فيما عدا محافظات الحدود.

\section{الاهنمام بالسياسة والمشاركة السياسية بين الشباب:}

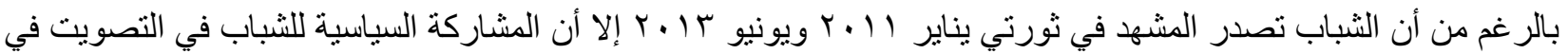

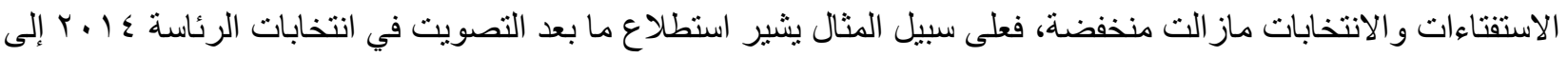

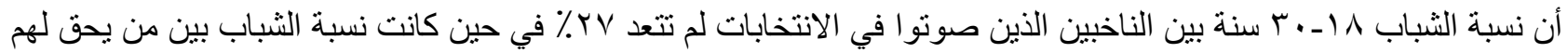

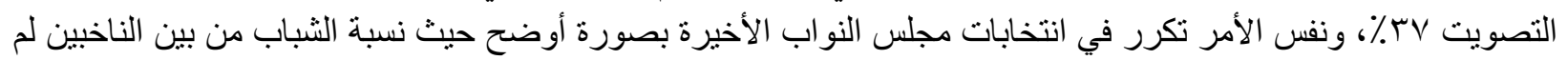

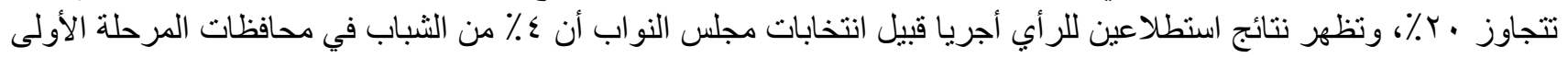

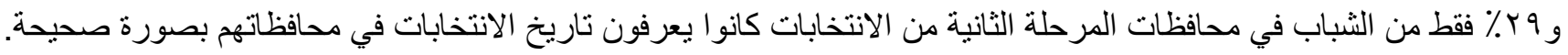
وهو ما يشير إلى عزوف نسبي بين الثباب عن المشاركة في الانتخابات. 
ويمكن عزو هذا العزوف إلى أن الثباب لا يشعرون بجدوى

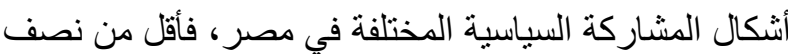

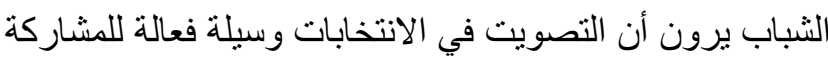

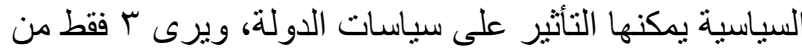

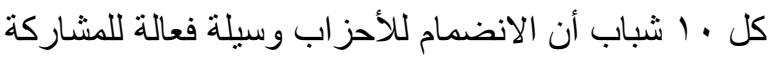

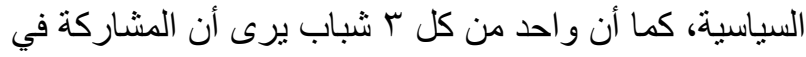
التظاهر ات و الاحتجاجات هي وسيلة فعالة للمشاركة السياسية،

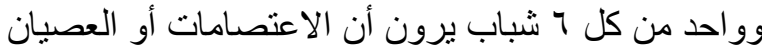
المدني وسيلة فعالة للمشاركة السياسية.

لم تحظ المشاركة في الأحز اب أو مساندتهم لها باهتمام الثباب

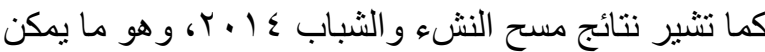

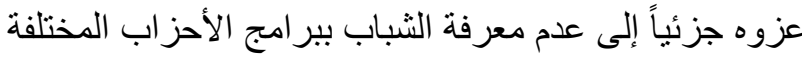
بصورة كافية، كما أن بـ ٪ من الثباب المصريين غير راضين

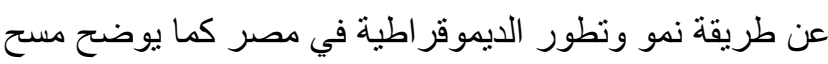
التحو لات الديموقر اطية في الوطن العربي.

ويوضح المسح الأخير ارتباط عزوف الثباب عن المشاركة

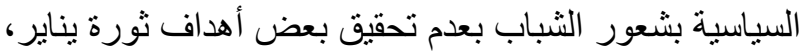

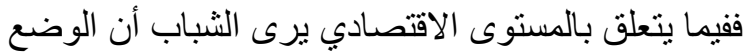

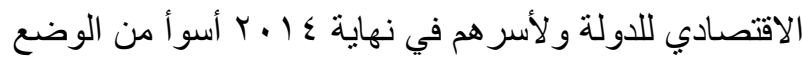
قبل ثورة يناير، كما يشعر الثباب بتحسن ضعيف فيما يتعلق

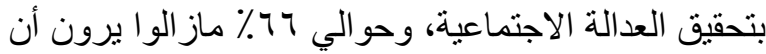

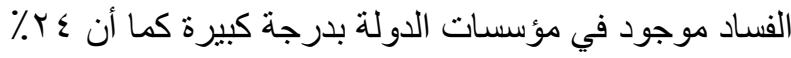

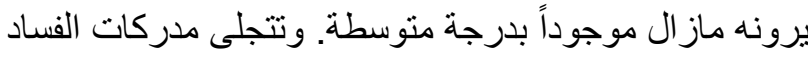

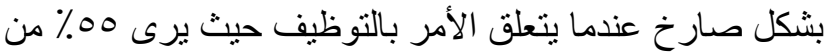

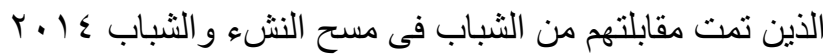
أن الحصول على وظيفة بستلزم عادةً واسطة لدرجة كبيرة، أما

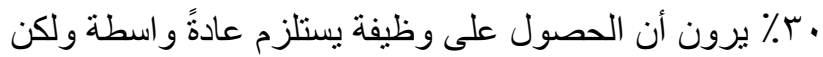

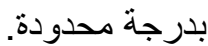

\section{التكنولوجيا والمشاركة السياسية}

أثرت التكنولوجيا على الوضع السياسي لمصر بشكلٍ كبير خلال السنوات الماضية فقد لعب الانترنت ووسائل الاتصال

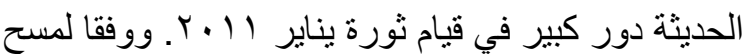

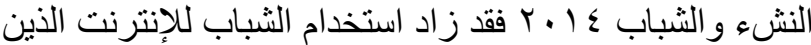

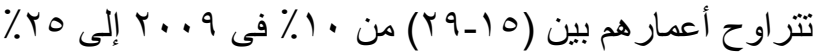

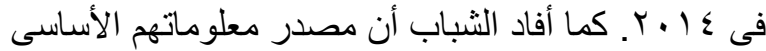

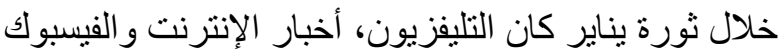

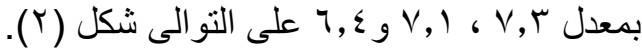

شكل ا: توزيع المؤهلين للانتخاب و الناخبين الذين

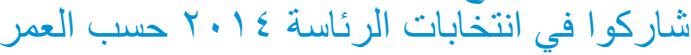

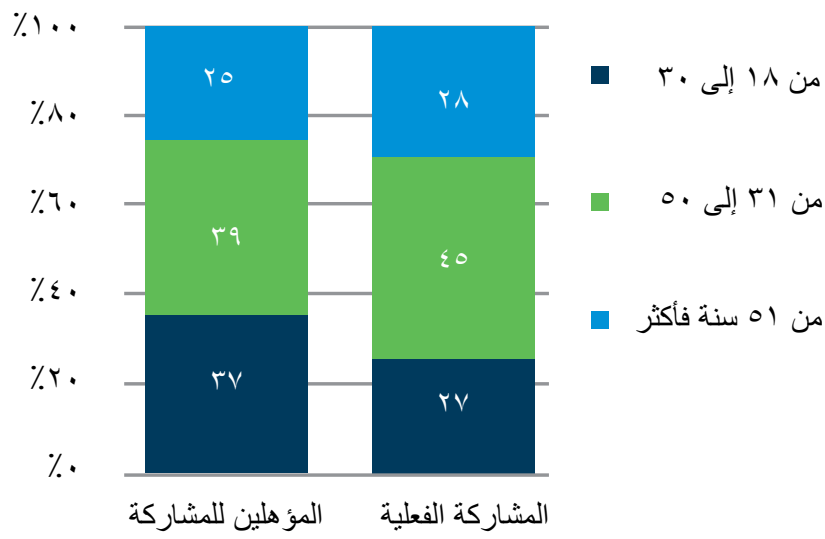

المصدر : الناخبين المؤ هلين للمشاركة: محسوب من إحصاءات الناخبين، اللجنة العليا

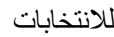

المشاركة الفعلية: استطلاع ما بعد التصويت في انتخابات الرئاسة ع ا ـ ب، بصيرة

ورغم أن الثباب المصري كانو ا دائماً الأقل رضا عن أداء

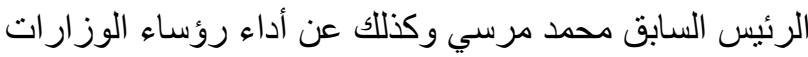

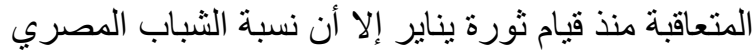

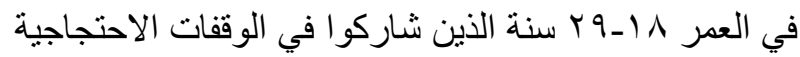
و المظاهرات ووقعو الوثيقة الخاصة بحركة تمرد لم تتجاوز

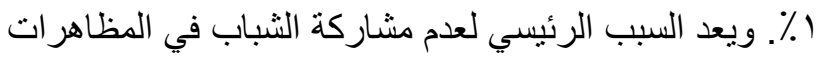

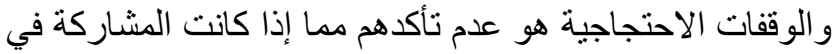

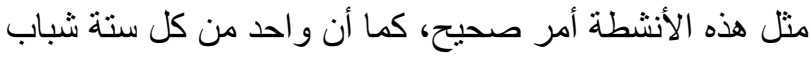

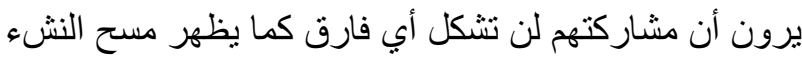

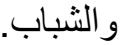

ويعكس سؤال مباثر للثباب عن تقييمهم لمدى اهتمامهح

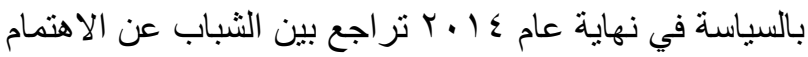

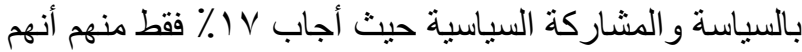

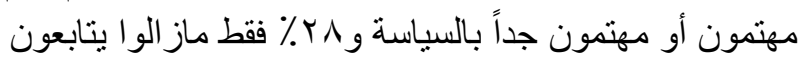

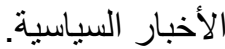

\section{الثقة في جدوى المشاركة السياسية:}

يأتي عزوف الثباب عن المشاركة السباسية في الوقت الذي مئي

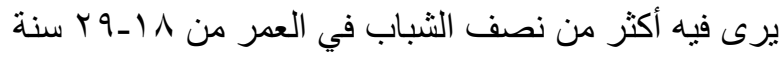

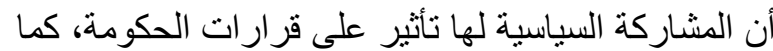

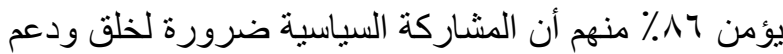
الديموقراطية في الدولة كما يظهر استطلاع المشاركة السياسية:

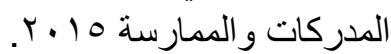




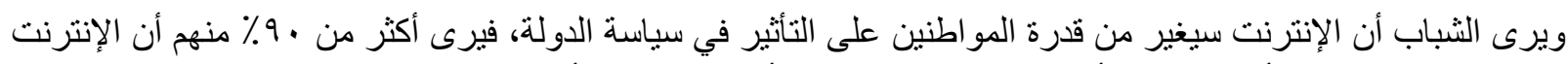

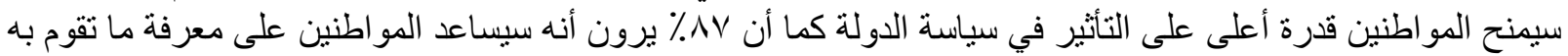

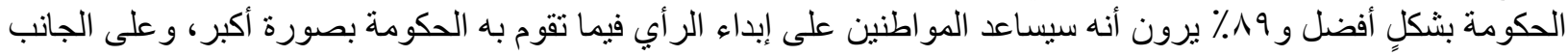

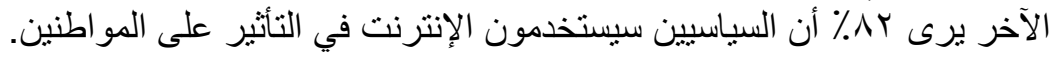

ويعتقد واحد من كل § شباب أن النشاط على شبكات التواصل الاجتماعي وسيلة فعالة للمشاركة السياسية يمكنها التأثير على قرار ات الدولة.

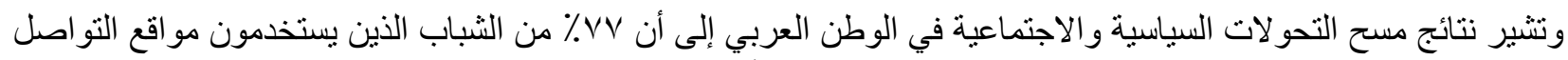

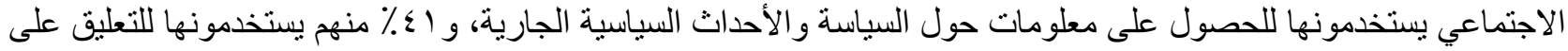

القضايا السياسية المختلفة.

شكل ץ: ترتيب الثباب المشاركين فى الأنشطة الثورية لأهمية المصادر المختلفة للمعلومات حول ثورة مب يناير

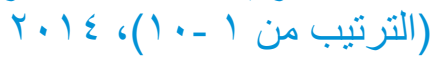

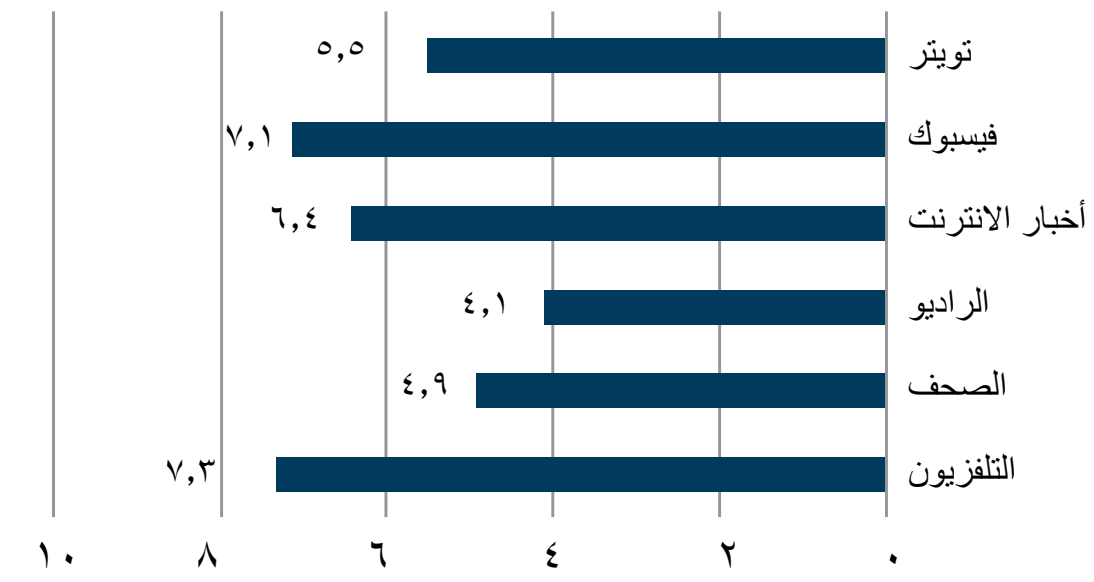

المصدر: مسح النشء و الثباب في مصر عـ ا.؟.

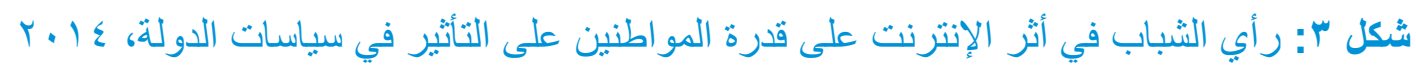

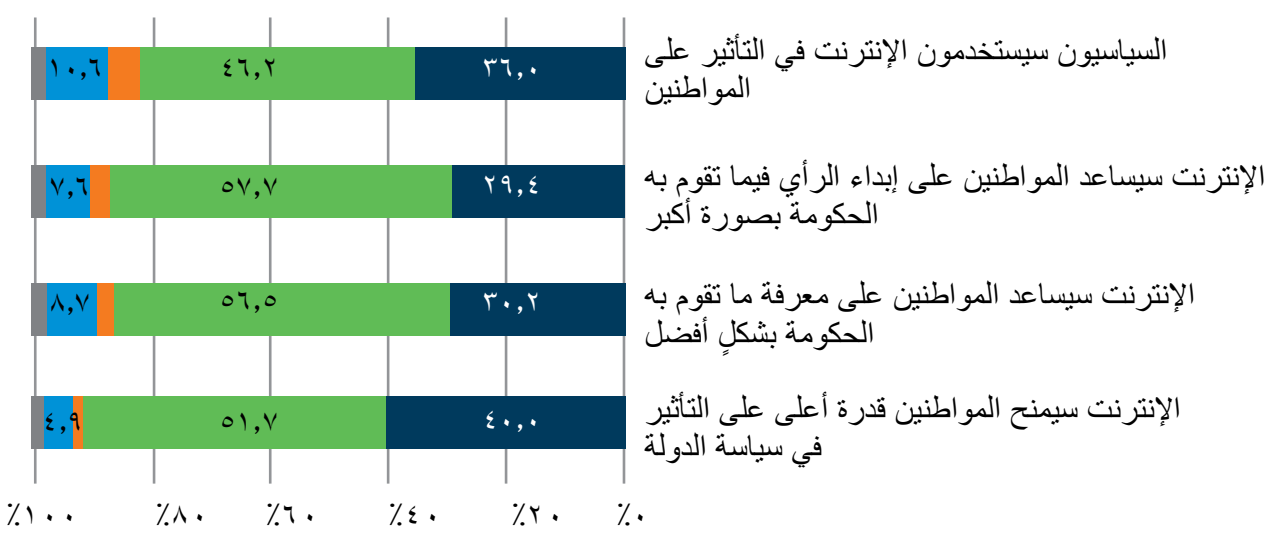

موافق جداً

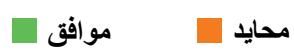

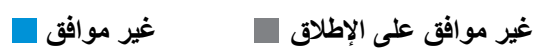

المصدر : مسح التحو لات الاجتماعية والسياسية في الوطن العربي، بصبرة. 


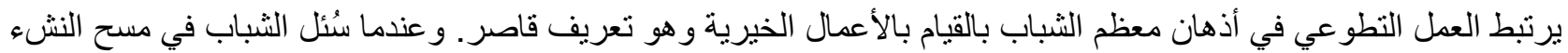

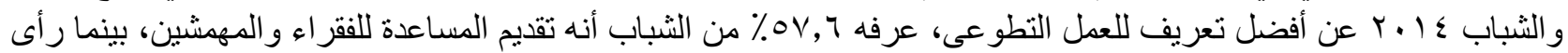

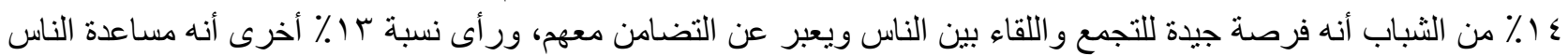

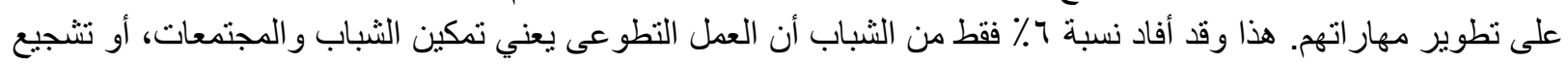
المو اطنة الفعالة.

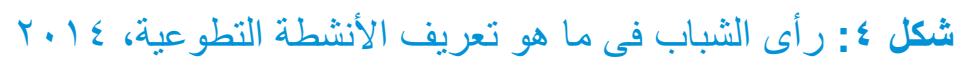

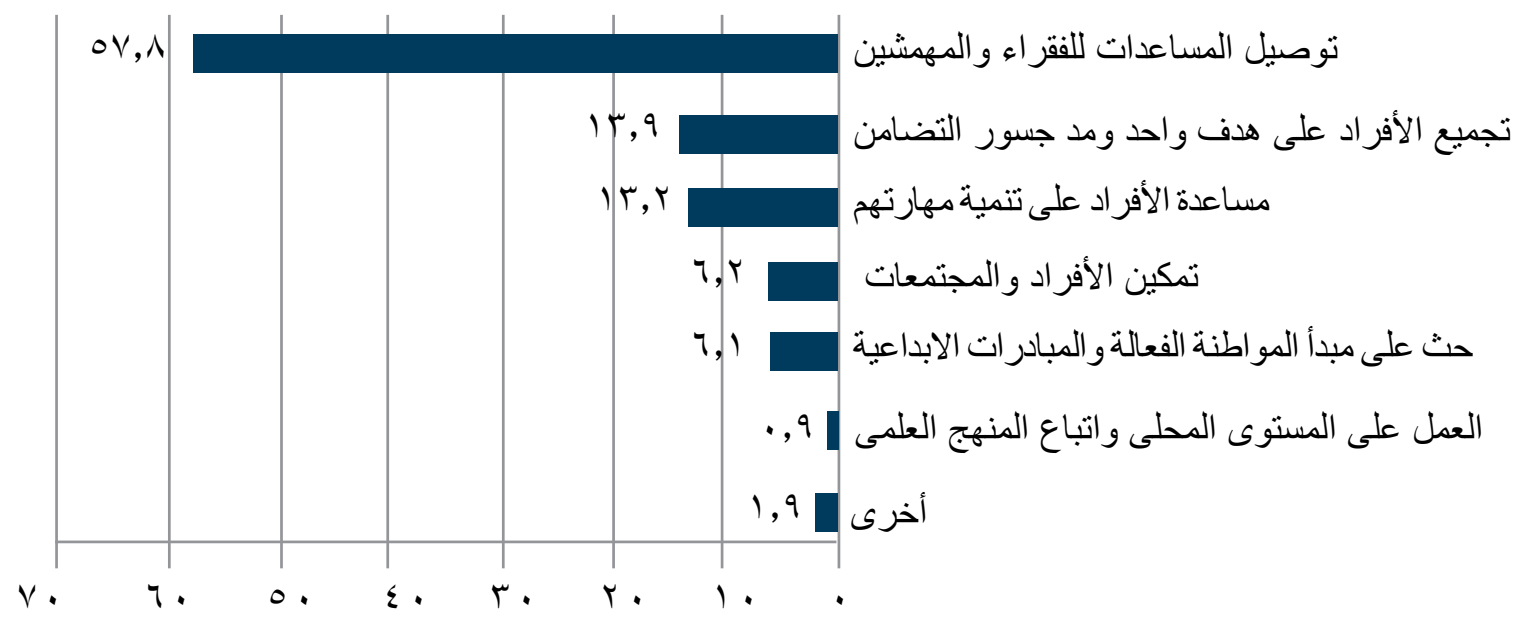

المصدر: مسح النشء و الثباب في مصر ع ا.ب.

وحتى في إطار هذا التعريف ماز الت المشاركة المجتمعية للثباب محدودة، فنسبة الثباب الأعضاء في جمعيات خيرية لا تتجاوز

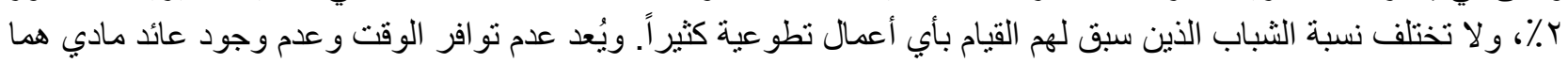
السبيين الرئيسيين في رأي الثباب، يليهما عدم تشجيع الأسرة.

و لا تتجاوز نسبة الثباب أعضاء النقابات أو الاتحادات العمالية أو غير ها ه٪ من إجمالي الثباب، وربما يرجع ذلك لارتباط عضوية هذه المؤسسات بشغل وظائف مهنية.

\section{السياسات اللازمة لتفعيل المشاركة السياسية والمجتمعية للثباب:}

هناك عدد من الفرص السانحة لتمكين الثباب وزيادة مشاركتهم تتمثل في نسبة الثباب الذين يشغلون مقاعد مجلس النو اب،

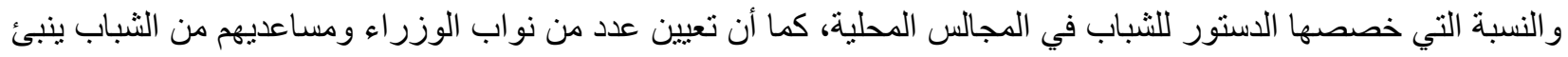
بتحول في المستقبل القريب يسمح لمزيد من الثباب بمشاركة أوسع في اتخاذ القرار وصنع السياسات التي ستشكل مستقبل مصر.

ويتطلب رفع مشاركة الثباب السياسية و المجتمعية مجمو عة من السياسات نوجز ها فيما يلي:

\section{ا . جذب الثباب للمشار كة السياسية و المتمعية:}

تتطلب زيادة مشاركة الثباب السياسية والاجتماعية تغيير رؤية الثباب لأهمية وجدوى المشاركة من خلال رسم مسار ات

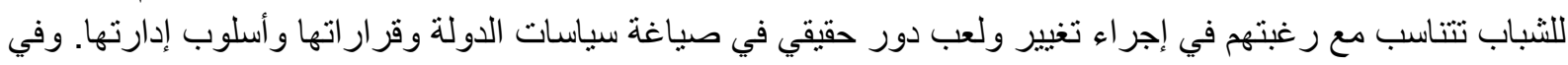

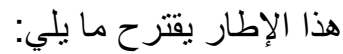


r. تفعيل مو اد الدستور:

يوجد عدد من المواد في الدستور المصري تهدف إلى زيادة المشاركة السياسية والاجتماعية للفئات

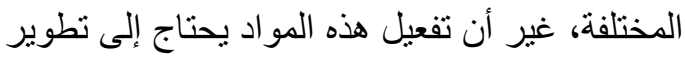

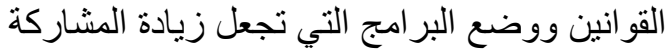

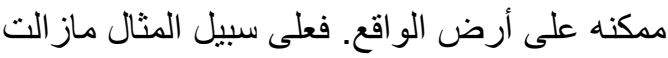
هنالك مشكلات تو اجه عمل الجمعيات الأهلية في فلي النيال

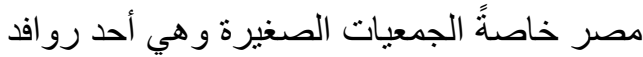
المجال العام التي يمكن من خلالها توظيف طاقة التها الثباب و إطلاق قدرنهم على الإبداع في التصدي

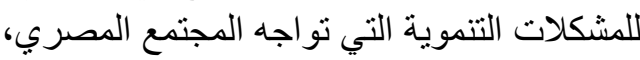
وهو ما يستدعي تطوير القوانين التي تحكم إنشاء جمعيات أهلية جديدة وتنظم أسلوب عملها.

\section{r. تفعيل دور الإعلام التقليدي في زيادة مشاركة

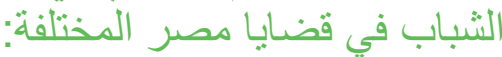

$$
\text { يلاحظ في السنو ات الأخيرة إنصر اف معظم }
$$
المصريين خاصةً الثباب عن متابعة الإعلام التقليدي الإني

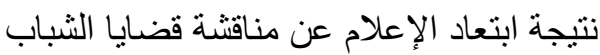

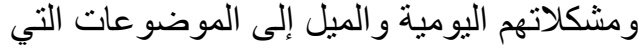

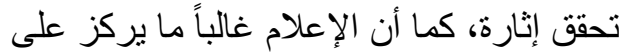

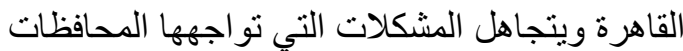

الصغيرة و المناطق الريفية. ويلاحظ أيضاً تجاهل الدراما المصرية للاور الإيجابي الذي لتئية يمكن أن يقوم

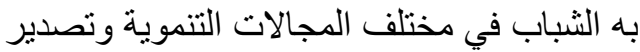

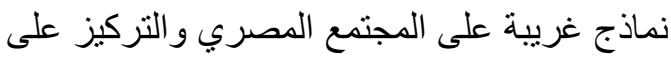
النماذج السلبية مما يضيع فرصة كبيرة على العيع الإعلام

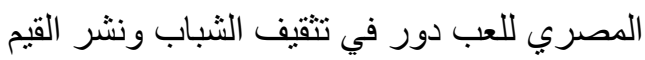
المو اتية للتنمية بينهم.
تشكيل لجان من الثباب تتبع مجلس النواب و المجالس المحلية يكون دور ها متابعة وتقييم تنفيذ

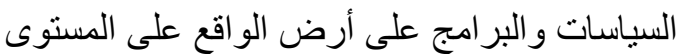

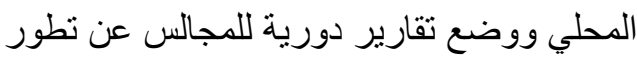
التنفيذ. كما يمكن أن تعقد هذه المجالس جلسات

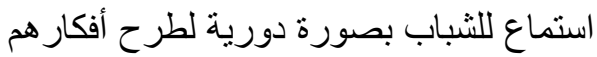
ومشكلاتهم والتوصل لحلول لها.

استخلال ارتباط الثباب بالإنترنت ومواقع

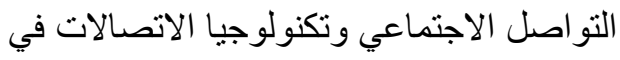
زيادة مشاركتهم السياسية والاجتماعية من خلال

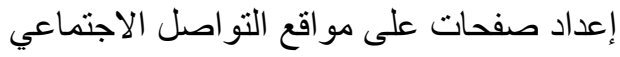

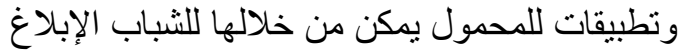

عن الظواهر السلبية في المجتمع كالعنف، الفساد

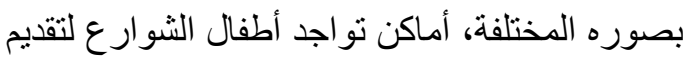
المساعدة لهم، و غير ها من الظو اهر الاجتماعية الهية

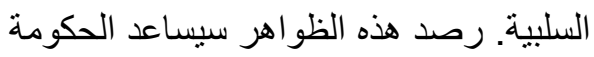
و الفاعلين المختلفين على وضع خطط مو اجنتها.

$$
\text { فتح قنوات للشباب للمشاركة في إعداد بر امج امج المبات }
$$

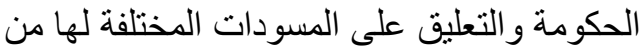
خلال عرضها على منصات التو اصل التل الاجتماعي

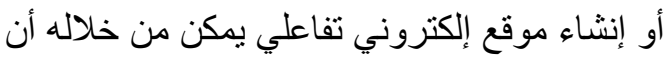
يوصل الثباب أصو اتهم للحكومة.

توظيف مر اكز الثباب وقصور الثقافة والمعسكرات

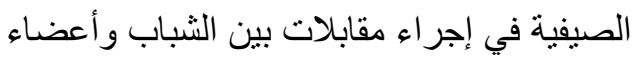
الحكومة و أعضاء البرلمان و المجالس المحلية

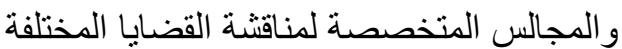
ووضع خطط للاستفادة من الثباب في مواجهة قضايا المجتمع المختلفة.

أطلقت وزارة الثباب موقع "بو ابة الثباب لمجلس النواب المصري". يحتوي الموقع على معلومات عن

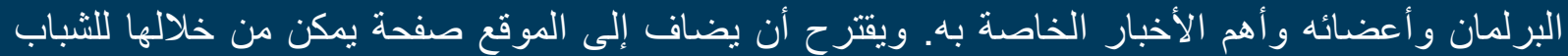
طرح أفكار هم لتوصيلها لأعضاء البرلمان، كما بمكن أن تسمح الصفحة للشباب بتقيبم اداء البراء البرلمان وتدوين 


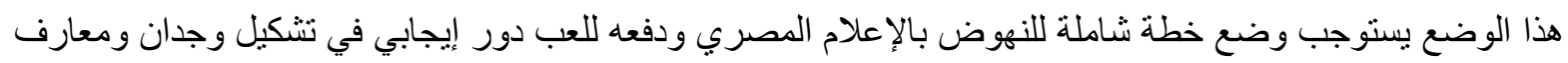

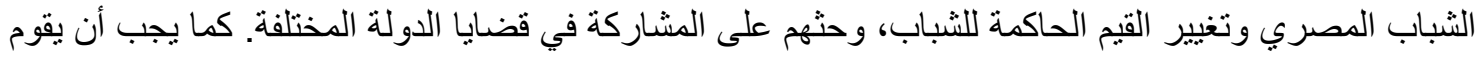
الإعلام بدور في تغيير الصورة الذهنية للمجتمع المصري عن الثباب و العمل على تقبل تقلدهم المناصب المخبل المختلفة ع. دور وزارة الثباب في المشاركة السياسية و المجتمعية للشباب:

يجب أن تلعب وزارة الثباب دوراً في تطوير مشاركة الثباب السياسية والمجتمعية للشباب من خلال تفعيل دور مر اكز الثباب و إنشاء منصات للتو اصل مع الثباب.

$$
\text { م. دور الأحز اب و الجمعبات الأهلية". }
$$

•على الأحزاب و الجمعيات الأهلية أن تعيد صياغة بر امجها و أنشطتها بصورة تجذب الثباب للمشاركة. 


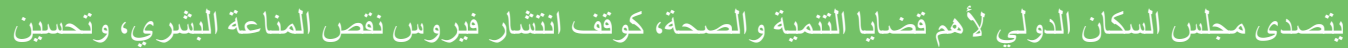

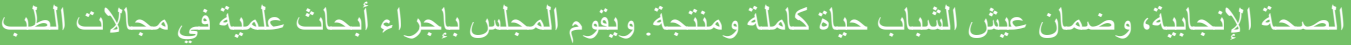

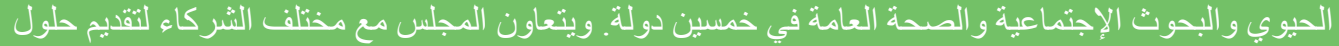

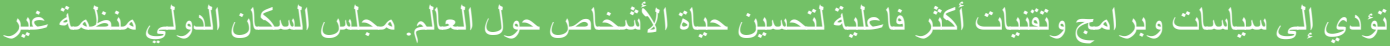

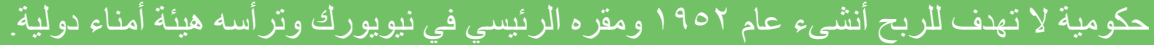

Population Council

One Dag Hammarskjold Plaza

New York, NY 10017

$$
\begin{aligned}
& \text { مجلس السكان الدولي - مصر }
\end{aligned}
$$

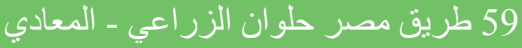

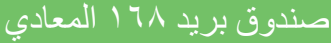

$$
\begin{aligned}
& \text { القاهرة - مصر بربد }
\end{aligned}
$$

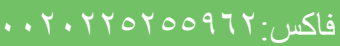

popcouncil.org

الإستشهاد المقترح: عثمان، ماجد وحنان جرجس.7 1 ـ ب. "نحو مشاركة فعالة للشباب؛، القاهرة: مجس السكان الدولى

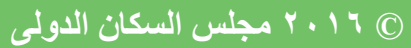

\section{POPULATION COUNCIL}

Ideas. Evidence. Impact.

(i) USAID

UN

Volunteers

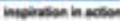

(2) FORDFOUNDATION

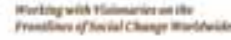

$\because \div$ (®) UNAIDS - (i) INFP unicef(2)

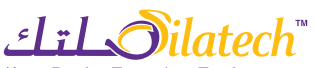
SWEDEN

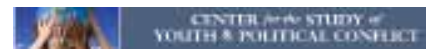
WOMEN DiP nonenting

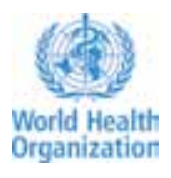

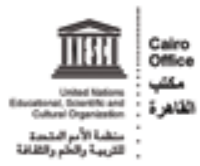

